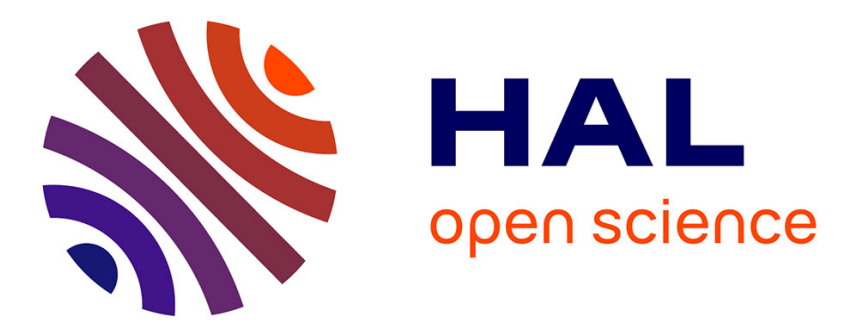

\title{
Measuring dislocation densities in nonpolar a-plane GaN films using atomic force microscopy
}

\author{
M A Moram, C F Johnston, M J Kappers, C J Humphreys
}

\section{To cite this version:}

M A Moram, C F Johnston, M J Kappers, C J Humphreys. Measuring dislocation densities in nonpolar a-plane GaN films using atomic force microscopy. Journal of Physics D: Applied Physics, 2010, 43 (5), pp.55303. 10.1088/0022-3727/43/5/055303 . hal-00569753

\section{HAL Id: hal-00569753 \\ https://hal.science/hal-00569753}

Submitted on 25 Feb 2011

HAL is a multi-disciplinary open access archive for the deposit and dissemination of scientific research documents, whether they are published or not. The documents may come from teaching and research institutions in France or abroad, or from public or private research centers.
L'archive ouverte pluridisciplinaire HAL, est destinée au dépôt et à la diffusion de documents scientifiques de niveau recherche, publiés ou non, émanant des établissements d'enseignement et de recherche français ou étrangers, des laboratoires publics ou privés. 
Measuring dislocation densities in nonpolar $a$-plane $\mathrm{GaN}$ films using atomic force microscopy

M. A. Moram ${ }^{\text {a) }}$, C. F. Johnston, M. J. Kappers, C. J. Humphreys

Dept. Materials Science \& Metallurgy, University of Cambridge, Pembroke St., Cambridge, CB2 3QZ, UK

Dislocation densities in nonpolar GaN films were determined using atomic force microscopy (AFM) by counting pits in the $\mathrm{GaN}$ surface revealed by a $\mathrm{SiH}_{4}$ surface treatment. This treatment increased the number of pits detected by a factor of 2 compared to the untreated surface. AFM and transmission electron microscopy analysis of a series of $\mathrm{SiH}_{4}$-treated calibration samples indicated that surface pit and dislocation densities corresponded well up to a dislocation density of $\sim 6 \times 10^{9} \mathrm{~cm}^{-2}$, above which surface pit overlap meant that dislocation densities determined by AFM were underestimated. For all samples with dislocations densities below $6 \times 10^{9} \mathrm{~cm}^{-2}$, spatial analysis of the surface pit positions showed that dislocations typically accumulated in bands at island coalescence boundaries.

Keywords: A1. Atomic force microscopy, A1. Line defects, A1. Planar defects, A3. Metalorganic vapour phase epitaxy, B1. Nitrides, B2. Semiconducting III-V materials

PACS codes: 61.72.Ff, 61.72.Lk, 61.72.Nn, 61.72.uj, 68.37.Ps, 81.05.Ea

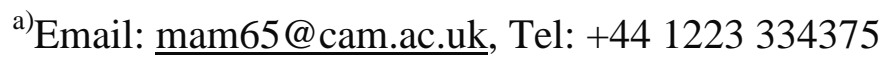


Since the development of the first efficient GaN-based blue light-emitting diode (LED) [1], wurtzite-structure $\mathrm{GaN}$ films with the polar $c$-plane crystal orientation have been used for LED production. These films are typically under significant levels of residual strain, as they are grown on non-native substrates with different lattice parameters and thermal expansion coefficients such as sapphire, silicon carbide or silicon. However, spontaneous polarization (due to the non-centrosymmetric wurtzite crystal structure) and piezoelectric polarisation (due to the presence of strain) occurs along the [0001] direction in all the hexagonal III-nitride materials, producing electric fields directed across the quantum wells in an LED based on $c$-plane material. This causes bending of the band structure in the region of the quantum wells and produces spatial separation of the electron and hole wavefunctions, giving rise to a reduced radiative recombination efficiency and an LED emission wavelength which is redshifted and which depends on the drive current. This effect (known as the quantum confined Stark effect $[2,3])$ can be avoided if quantum wells are grown on GaN films having alternative crystalline orientations [4]. In the case of nonpolar (a-plane) GaN, the electric fields should be directed parallel to the quantum wells and should thus have little effect on the band structure across the quantum wells, giving flat band conditions and potentially allowing greater device efficiencies to be reached. Therefore, interest in the growth of $\mathrm{GaN}$ in the nonpolar $a$-plane (11-20) and $m$-plane (1-100) orientations is increasing. Recent results for InGaN/GaN quantum wells grown on low defect-density $m$-plane GaN substrates show that high efficiencies and minimal wavelength dependence on drive current can indeed be achieved [5]. However, in order to achieve those results, small-area slices had to be cut from expensive, thick HVPE-grown GaN pseudo-substrates. In order to produce these devices at a reasonable cost, nonpolar GaN films must be grown on cheaper 
conventional substrates such as sapphire. Currently, defect densities for heteroepitaxially grown nonpolar GaN films are extremely high, and these defects are thought to dominate the performance of devices fabricated from nonpolar heteroepitaxial GaN films; for example, radiative recombination at energies below that of the band gap can occur at basal-plane stacking faults and at impurities decorating partial dislocations $[6,7]$. Defect reduction in nonpolar $\mathrm{GaN}$ is thus a topic of considerable current research interest $[8,9,10]$, and accurate dislocation density determination is crucial for optimising material quality for LED production.

The predominant defect types in nonpolar GaN are basal-plane stacking faults (BSFs), which include intrinsic BSFs of the $\mathrm{I}_{1}$ (stacking sequence $\mathrm{AB} \underline{\mathrm{ABCBCBC}}, \mathrm{I}_{2}$

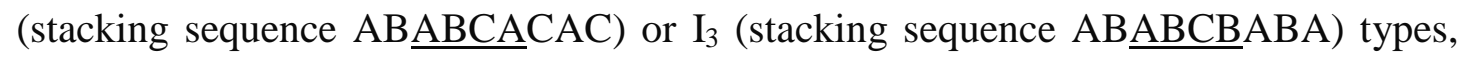
along with extrinsic SFs with a stacking sequence of ABABCABAB. $\mathrm{I}_{1}$-type SFs are bounded by sessile Frank partial dislocations with $\mathbf{b}=1 / 6<20-23\rangle, \mathrm{I}_{2}$ SFs are bounded by dislocations with $\mathbf{b}=1 / 3<1-100>$ and extrinsic SFs are bounded by Frank partials with $\mathbf{b}=1 / 2[0001][11,12]$. The stacking fault energy increases and the probability of fault formation decreases on progressing from $I_{1}$ through $I_{2}$ and $I_{3}$ to extrinsic BSFs, due to the increasing number of mis-stacked bilayers involved in each case. As a result, only $\mathrm{I}_{1}$-type BSFs are usually observed [13]. BSFs in gallium nitride are known to be optically active; a strong emission at $3.14 \mathrm{eV}$ has been reported from BSFs [14], which are thought to act like quantum wells of cubic (zinc-blende) GaN embedded in a hexagonal (wurtzite) GaN matrix [15]. Electronically, BSFs are thought to act as anisotropic scattering centres for electrons and holes [16] and are associated with band discontinuities [16] and local electric fields oriented along the [0001] direction [13], producing in-plane carrier separation and junction leakage currents [17]. 
Prismatic stacking faults (PSFs) along the (-12-10) plane with a displacement vector $\mathbf{R}=1 / 2[10-11]$ can also be present, along with perfect edge-type dislocations with $\mathbf{b}=$ $1 / 3$ [11-20] [11]. The partial dislocations (PDs) which terminate BSFs may also be associated with increased junction leakage currents [17] and are thought to act as nonradiative recombination centres [18]. Total threading dislocation densities in heteroepitaxial films are typically $10^{9}-10^{10} \mathrm{~cm}^{-2}$ and total BSF densities are typically $10^{5}-10^{6} \mathrm{~cm}^{-1}[11,12]$. The high defect densities and the wide variety of possible defect types make defect density determination in nonpolar $\mathrm{GaN}$ more challenging than in conventional $c$-plane GaN. So far, defect densities have been determined using transmission electron microscopy (TEM, which involves expensive equipment and which requires time-consuming, skillful sample preparation $[8,9])$ and it has proven very difficult to relate data obtained using more rapid techniques (such as XRD) to defect densities [19, 20, 21, 22].

It is well-known that small pits typically form where threading dislocations intersect the surface of $c$-plane GaN films, with the pits due to mixed or screw dislocations being wider and deeper than those due to edge dislocations. Previous studies have shown that such pits can be enlarged using an in-situ post-growth $\mathrm{SiH}_{4}$ treatment, allowing total dislocation densities to be determined accurately using atomic force microscopy (AFM) [23]. AFM studies of laterally overgrown nonpolar films have also revealed that a high pit density is present in the seed regions of the film, whereas a low pit density is present in the wing region of the films [24]. In this paper, we investigate the possibility of using the surface pits present on nonpolar GaN films as a guide to defect densities. 
A series of $a$-plane (nonpolar) $\mathrm{GaN}$ films were grown on $r$-plane sapphire using a Thomas Swan close-coupled showerhead metal-organic vapour phase epitaxy reactor. For Samples A, B and C, the V-III precursor ratio was varied at the initial stages of growth [10]. For Sample D, multiple $\mathrm{SiN}_{\mathrm{x}}$ interlayers were used [25] and for Sample $\mathrm{E}$, a single $5 \mathrm{~nm} \mathrm{ScN}$ interlayer was used $[8,26]$. These different growth techniques produced a range of defect types and densities in the films, as summarised in Table 1. Following growth, a $\mathrm{SiH}_{4}$ treatment $\left(860{ }^{\circ} \mathrm{C}, 4 \mathrm{~min}\right)$ was applied to highlight the pits formed where the PDs intersected the film surface, according to the method employed in Ref. 17 for highlighting surface pits in $c$-plane films. AFM studies of the film surfaces were carried out in tapping mode using a Digital Instruments Dimension 3100 microscope, using standard Si tips with a radius of $30-40 \mathrm{~nm}$. Subsequent AFM data analysis was carried out using the WSxM software [27]. Spatial analysis techniques were used to investigate the spatial arrangement of the PDs, as revealed by the locations of the surface pits in AFM amplitude images [28, 29, 30]. Plan-view transmission electron microscopy (TEM) was used to investigate the defect densities of the samples. Plan-view TEM samples were prepared using mechanical polishing, followed by ion beam thinning to electron transparency. Subsequent analysis was carried out using a $300 \mathrm{kV}$ Philips CM30 electron microscope. Dislocation densities were determined from plan-view TEM images taken using $\mathbf{g}=0002$, in which partial dislocations (PDs, $\mathbf{b}=1 / 6<20-23>)$, pure $(a+c)$-type dislocations $\left(\mathbf{b}={ }^{1} / 3<11-23>\right)$ and pure $c$-type dislocations $(\mathbf{b}=<0001>$ ) are in contrast. The basal plane stacking fault (BSF, $\mathbf{R}=1 / 6<20-23>$ ) density in each sample was also determined from plan-view TEM images taken using $\mathbf{g}=1-100$. BSF densities were calculated by measuring the total length of stacking faults per unit area [10]. 
In practice, due to the long length-scale roughness found in most of these samples, it is found that the pits associated with dislocations can be located and counted with greater ease using AFM amplitude data, although pit depths must be measured using AFM topography data. The AFM amplitude images shown in Fig. 1 illustrate the effects of the $\mathrm{SiH}_{4}$ surface treatment. Prior to treatment, some shallow surface pits can be detected. However, following $\mathrm{SiH}_{4}$ treatment, the pits appear enlarged and the number of pits that can be detected increases by a factor of two. Fig. 2 shows a histogram of the pit depths for a $\mathrm{SiH}_{4}$-treated film, indicating an average detected pit depth of $1.2 \mathrm{~nm}$ for the standard AFM tip used (of course, the apparent pit depths will vary depending on the radius of the AFM tip used, as sharper tips will penetrate more deeply into the pits). In contrast to the bimodal pit depth distribution observed following $\mathrm{SiH}_{4}$ treatment of $c$-plane $\mathrm{GaN}$ films (where both $a$-type and $(a+c)$-type dislocations are present), a skewed unimodal distribution of pit depths is observed for $a$-plane GaN films. A comparison of TEM images showing BSFs with TEM images of the same area showing dislocations indicated that most dislocations terminated BSFs, meaning that they were PDs. More specifically, an average of $92 \%$ of the dislocations across all samples analysed were PDs, whereas $8 \%$ were pure $a$-type dislocations; little variation between samples was seen. As over 1000 dislocation pits were counted for each film, the statistics employed would have been sufficient to distinguish an $8 \%$ difference between the total dislocation densities detected by TEM and the dislocation pit densities detected by AFM. For lower dislocation densities, no significant discrepancy between the two measurements was detected: the surface pits can be resolved easily and their densities correspond well to the dislocation densities measured using TEM. Therefore, we conclude that the $\mathrm{SiH}_{4}$ treatment highlights all types of dislocations, not just PDs. This is in contrast to conventional $\mathrm{KOH}$ treatment, 
which etches micron-sized anisotropic features into the film surface and which does not reveal PDs successfully [31]. However, for nonpolar films with high PD densities, the pits in some regions of the film begin to merge together, limiting the accuracy with which pit densities can be obtained. The extent of such apparent pit merging is also affected by the surface topography (which is in turn dependent upon film growth conditions), with pits being particularly difficult to distinguish on films having significant nanoscale surface roughness. As a result, for samples with a high PD density approaching $10^{10} \mathrm{~cm}^{-2}$ the detected pit density was lower than the known PD density, as determined using TEM. These data are summarised in the calibration plot shown in Fig. 3.

For the $\mathrm{SiH}_{4}$-treated samples, we find that the surface pits are elongated parallel to the [0001] direction, with the pit length being approximately twice the pit width (the tip scan direction was changed and the data were re-checked to ensure that this was not a tip-related anomaly). This is in contrast to the symmetrical dislocation pits that are observed following $\mathrm{SiH}_{4}$ treatment of $c$-plane $\mathrm{GaN}$ films. As the dislocation pits are enlarged after exposure to $\mathrm{SiH}_{4}$, some etching must occur during this treatment. Micron-sized anisotropic pits have previously been observed during the coalescence of nonpolar GaN films [32] and these were attributed to different growth rates on different crystal facets. The different bonding configurations at the crystal facets exposed where the dislocation intersects the sample surface are also likely to lead to anisotropic etching rates around the pit when the film is treated with $\mathrm{SiH}_{4}$ at elevated temperatures, producing enlarged, anisotropic dislocation pits. Even though it is possible for their Burgers vectors to point in different directions, the individual Burgers vector of the dislocation does not have any detectable effect on the shape of 
the dislocation pits. This is similar to the case of dislocations in $c$-plane GaN, which produce rotationally symmetrical surface pits regardless of the individual Burgers vector of the dislocation.

Furthermore, it has been observed experimentally that surface pit densities correspond well to PD densities for $\mathrm{SiH}_{4}$-treated films where the film is smooth enough to permit linear features (extended linear 'dips' in the surface) running perpendicular to the [0001] direction to be seen (e.g. Fig. 1(b)). The extended linearity and crystallographic orientation of these additional features revealed by the $\mathrm{SiH}_{4}$ treatment suggests that they might occur where BSFs intersect the film surface. Indeed, close inspection shows that these linear features are generally terminated by dislocation pits, as expected for BSFs. Other authors have also observed these features, and attributed them to BSFs, although no comparison to TEM data was made [33]. However, we find that the density of these linear features is approximately one order of magnitude less than the total BSF density (as determined by TEM). Although four types of BSF could occur in these wurtzite-structure films, the possibility that the striations are related to a different, less prevalent type of BSF can be ruled out, as only $\mathrm{I}_{1}$-type BSFs have been observed in these samples [13, 34]. Instead, it is likely that such features arise only where $\mathrm{I}_{1}$-type BSFs happen to be closely spaced.

For $\mathrm{SiH}_{4}$-treated samples where the PD densities corresponded well to surface pit densities, the locations of the surface pits were recorded and spatial analysis was used to detect whether the PDs were randomly distributed or whether spatial ordering or clustering was present. Fig. 4 shows the corrected radial distribution function relating to pit locations obtained for Sample E, in which the very smooth surface allows the 
easy identification and location of pits over large-area AFM scans. Monte Carlo simulations were used to determine the $99 \%$ confidence intervals; where the data exceed these confidence intervals, spatial clustering is indicated. Such clustering of PDs occurs on length scales extending as far as $600 \mathrm{~nm}$, though a peak at $100 \mathrm{~nm}$ can be distinguished; inspection of the original data indicates that the clustering takes the form of PDs concentrated around the edges of broad regions with significantly lower PD density. For samples with a rougher surface, such as Sample C (Fig. 5), the PD distribution is clearly related to the surface morphology, with PDs being more abundant at the boundaries of the surface striations. Bands of PDs can also be seen crossing the striations at intervals. These data provide insight into the microstructural development in these samples, suggesting strongly that the islands present during the early stages of film growth nucleate and grow outwards until they coalesce, whereupon the PDs terminating the BSFs are 'locked' into place at the coalescence boundaries.

Overall, it is clear that defect densities in these nonpolar heteroepitaxial films are still too high for practical use in devices. Although it is widely accepted that for $c$-plane $\mathrm{GaN}$, a threading dislocation density of less than $10^{7} \mathrm{~cm}^{-2}$ is needed for optoelectronic devices (ideally less than $10^{6} \mathrm{~cm}^{-2}$ for laser diodes), the partial dislocations found in nonpolar GaN do not have the same properties as the edge, mixed or screw dislocations found in $c$-plane $\mathrm{GaN}$ and the dislocation density might need to be lower for nonpolar devices due to the leakage currents associated with BSFs and PDs [17]. While the combination of multiple $\mathrm{SiN}_{\mathrm{x}}$ or $\mathrm{ScN}$ interlayers is likely to improve the quality of the material further, growth conditions would need to be optimised in order to achieve rapid coalescence, so as to avoid the build-up of excessive strain. In 
particular, conditions favouring the growth on the Ga-face (0001) GaN planes should be used, as growth on the N-face (0001) planes is associated with BSF formation [35]. Surface roughnesses must also be controlled, both for good device performance and for ease of dislocation density quantification. However, in the search for the most successful defect reduction method, the dislocation density quantification method presented in this paper will be useful for monitoring the effectiveness of defect reduction strategies.

In conclusion, AFM studies of the surfaces of nonpolar $a$-plane GaN films grown using different defect reduction methods have revealed the presence of surface pits elongated along the [0001] direction which are associated with threading dislocations, consistent with previous work [25, 31, 33]. However, the density of these pits (as detected by AFM) is lower than the true dislocation density, as revealed by TEM. In order to enlarge the pits and allow all dislocations to be detected, a post-growth $\mathrm{SiH}_{4}$ treatment can be applied, which enables dislocations to be detected, for dislocation densities below $\sim 6 \times 10^{9} \mathrm{~cm}^{-2}$. A comparison with plan-view TEM images of the same films indicates that surface pits are associated with both partial dislocations (PDs) and pure $a$-type dislocations, enabling the total dislocation density to be assessed. This method is much more effective for monitoring dislocation densities than conventional $\mathrm{KOH}$ etching, which does not reveal PDs clearly [31]. However, at PD densities above $\sim 6 \times 10^{9} \mathrm{~cm}^{-2}$, the density of pits that can be detected using AFM becomes less than the true density of PDs. This is attributed to the overlap of pits which occurs in regions of locally high PD densities, for example, near island coalescence boundaries. The $\mathrm{SiH}_{4}$ treatment also reveals linear surface features which run perpendicular to [0001] with a density approximately one order of magnitude 
lower than the BSF density. These features probably arise from closely spaced $\mathrm{I}_{1}$-type BSFs. For samples with lower PD densities, studies of the spatial distribution of the surface pits associated with PDs reveal that PDs are not randomly distributed but tend to cluster together in bands, a finding which is consistent across films grown using different defect density reduction techniques. These data are consistent with the accumulation of PDs at island coalescence boundaries.

\section{Acknowledgements}

MAM would like to thank the Oppenheimer Trust and Jesus College, Cambridge for personal fellowships. This work was supported by the EPSRC under grant no. EP/EC035167/1. 


\section{References:}

[1] Nakamura S, Senoh M and Mukai T 1993 Appl. Phys. Lett. 622390

[2] Takeuchi T et al.1997 Jpn. J. Appl. Phys. 36 L382

[3] Miller D A B et al. 1985 Phys. Rev. B 321043

[4] Waltereit P et al. 2000 Nature 406865

[5] Schmidt M C et al. 2007 Jpn. J. Appl. Phys. 46 L126

[6] Liu R et al. 2005 Appl. Phys. Lett. 86021908

[7] Paskov P P et al. 2005 J. Appl. Phys. 98093519

[8] Moram M A et al. 2009 J. Cryst. Growth 3113239

[9] Johnston C F et al. 2009 J. Cryst. Growth 3113295

[10] Haskell B A et al. 2007 Phys. Status Solidi B 2442847

[11] Johnston C F et al. 2009 Phys. Status Solidi A 2061190

[12] Zakharov D et al. 2005 Phys. Rev. B 71235334

[13] Metcalfe G D et al. 2008 Appl. Phys. Lett. 92241106

[14] Liu R et al. 2005 Appl. Phys. Lett. 86021908

[15] Corfdir P et al. 2009 J. Appl. Phys. 105043102

[16] McLaurin M and Speck J S 2007 PSS RRL 1110

[17] Chakraborty A et al. 2005 Jpn. J. Appl. Phys. 44 L173

[18] Wu Z H et al. 2008 Appl. Phys. Lett. 92171904

[19] McLaurin M B et al. 2008 Jpn. J. Appl. Phys. 475429

[20] Moram M A et al. 2009 J. Appl. Phys. 105113501

[21] Moram M A, et al. 2009 Physica B 4042189

[22] Moram M A and Vickers M E 2009 Rep. Prog. Phys. 72036502

[23] Oliver R A et al. 2006 J. Cryst. Growth 289506 
[24] Hollander J L et al. 2007 Physica B 401307

[25] Kappers M J et al. 2008 J. Cryst. Growth 3104983

[26] Moram M A et al. 2007 Appl. Phys. Lett. 91152101

[27] Horcas I et al. 2005 Rev. Sci. Instrum. 78013705

[28] Fortin M J and Dale M 2005 Spatial Analysis, A Guide For Ecologists, (Cambridge University Press)

[29] Perry G L W 2004 Env. Modell. \& Soft. 19559

[30] Moram M A et al. 2009 Adv. Mater. 213941

[31] Wei T 2008 Jpn. J. Appl. Phys. 473346

[32] Craven M D et al., 2004 Appl. Phys. Lett. 841281

[33] Haskell B A et al. 2005 J. Electron. Mater. 34357

[34] Liu L and Humphreys C J (unpublished)

[35] Cho Y S et al. 2008 Appl. Phys. Lett. 93111904 


\section{Figure captions}

Figure 1. (a) $3 \mu \mathrm{m} \times 3 \mu \mathrm{m}$ AFM amplitude image of Sample E (untreated) and (b) 3 $\mu \mathrm{m}$ x $3 \mu \mathrm{m}$ AFM amplitude image of Sample E (treated with $\mathrm{SiH}_{4}$ ). Arrows indicate the [0001] direction.

Figure 2. Histogram of pit depths after a $\mathrm{SiH}_{4}$ surface treatment, showing a unimodal distribution (Sample E).

Figure 3. Plot of surface pit densities detected using AFM versus the partial dislocation (PD) density detected using TEM, for a series of nonpolar $a$-plane GaN films. The dotted line indicates the trend on which the data should fit if each PD is associated with a surface pit that can be detected using AFM.

Figure 4. (a) $5 \mu \mathrm{m}$ x $5 \mu \mathrm{m}$ AFM amplitude image of Sample E showing dislocation pits aligned along boundaries; (b) corrected radial distribution functions of pit positions for Sample E (data obtained from multiple AFM scans), where black symbols indicate data points and grey symbols indicate the $99 \%$ confidence intervals within which spatially random data should lie.

Figure 5. $2 \mu \mathrm{m} \times 2 \mu \mathrm{m}$ AFM topography image of Sample C showing bands of PDs aligned both along and across surface striation boundaries (PD positions highlighted using white dots). 


\section{Table caption}

Table 1. Defect densities (from plan-view TEM) and surface roughnesses (from AFM) of the samples investigated in this study. The roughness values were obtained from line-flattened $20 \mu \mathrm{m}$ x $20 \mu \mathrm{m}$ AFM topography scans. 
Table

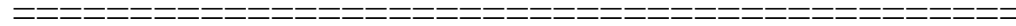

\begin{tabular}{llll} 
Sample & Dislocation & BSF & r.m.s. surface \\
ID & density & density & roughness \\
& $\left(\times 10^{10} \mathrm{~cm}^{-2}\right)$ & $\left(\times 10^{5} \mathrm{~cm}^{-1}\right)$ & $(\mathrm{nm})$ \\
& & \\
\hline
\end{tabular}

$\begin{array}{llll}\text { A } & 2.5 \pm 0.3 & 11 \pm 2 & 24\end{array}$

$\begin{array}{llll}\text { B } & 2 \pm 0.3 & 4.6 \pm 0.5 & 72\end{array}$

$\begin{array}{llll}\text { C } & 0.36 \pm 0.02 & 3.0 \pm 0.5 & 98\end{array}$

D $\quad 0.66 \pm 0.04 \quad 3 \pm 0.3 \quad 95$

$\begin{array}{llll}\text { E } & 0.18 \pm 0.02 & 5.9 \pm 0.8 & 4\end{array}$ 


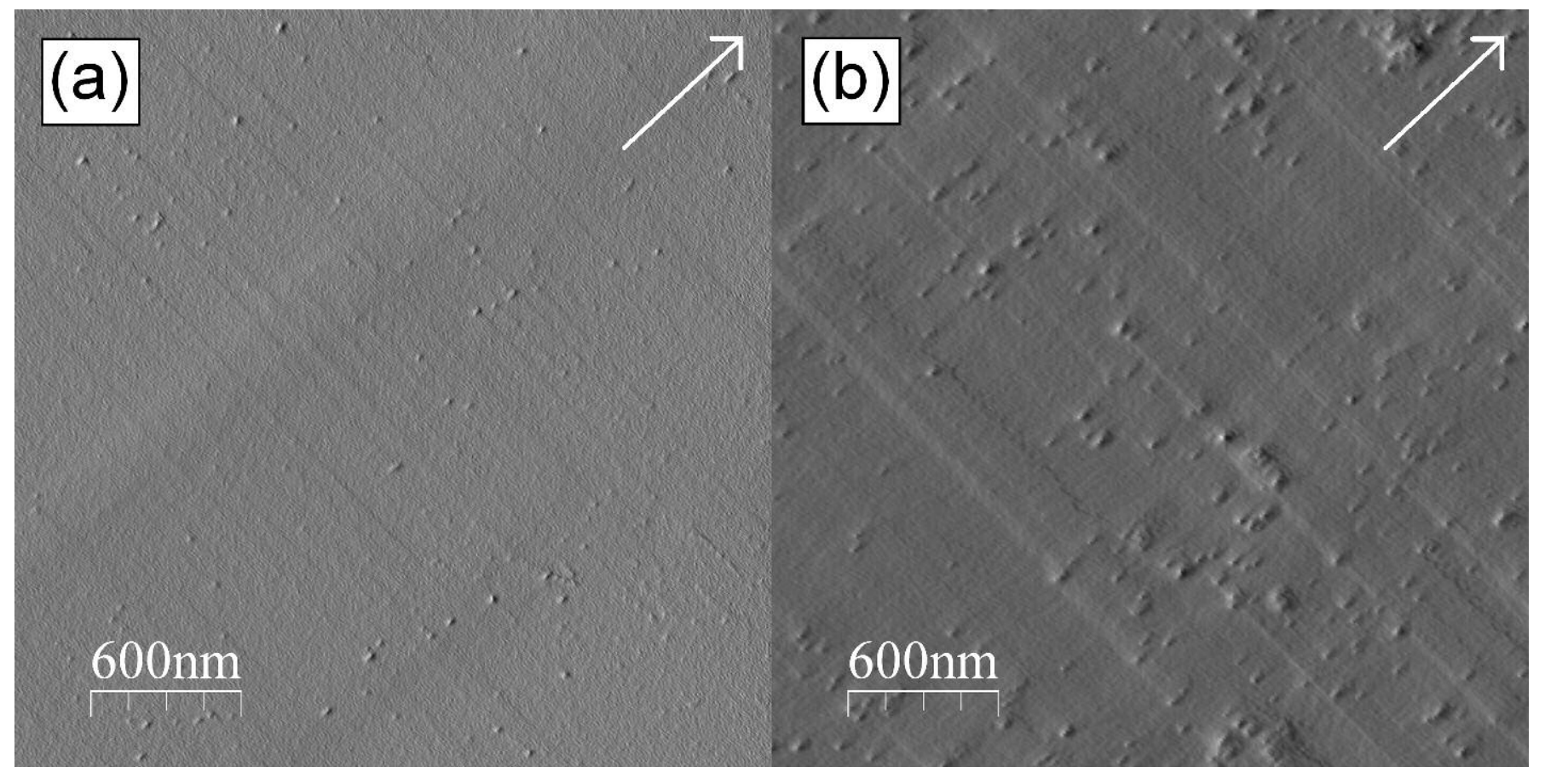

Figure 1 (FIG-1.tif) 


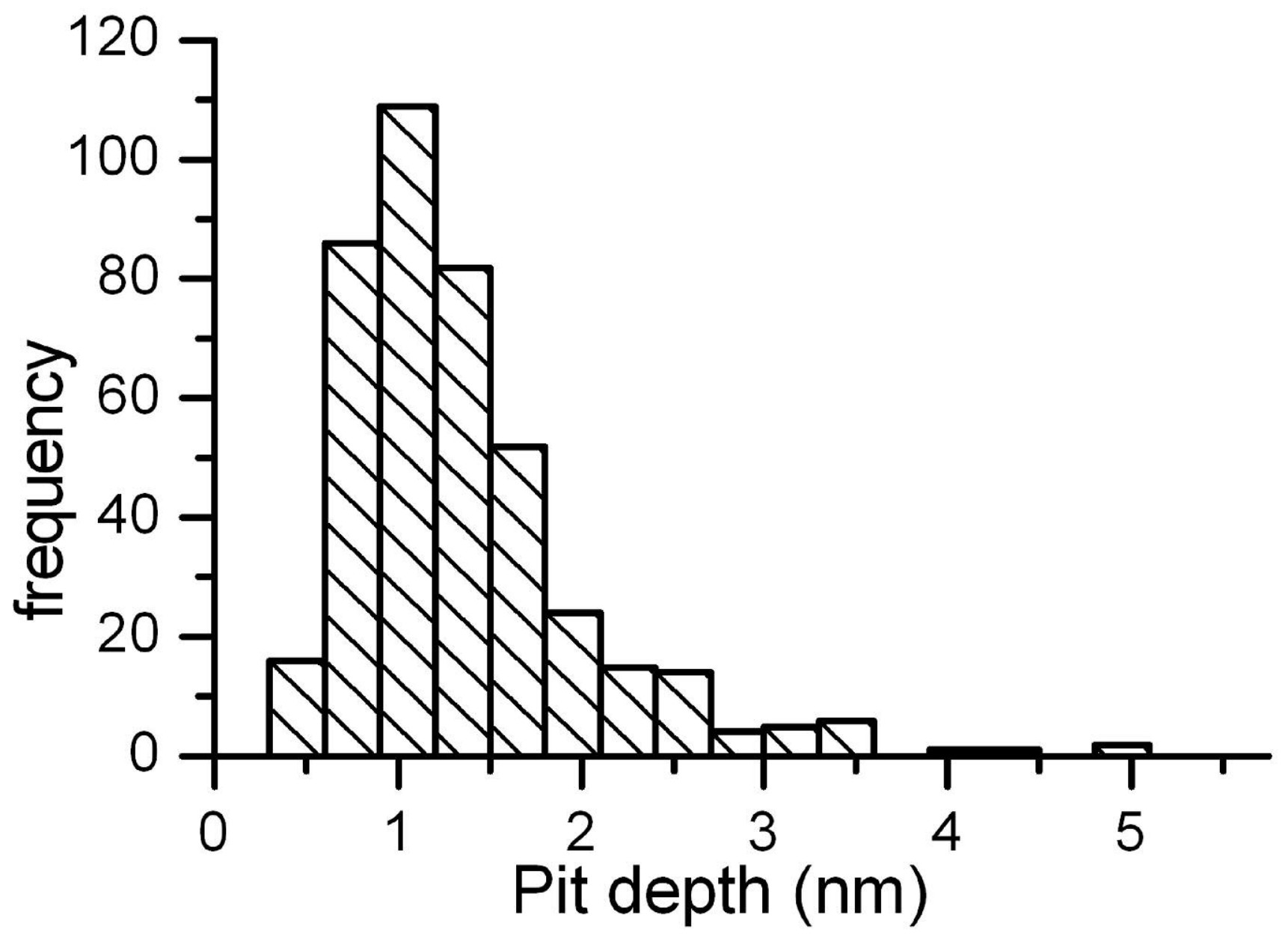

Figure 2 (FIG-2.tif) 


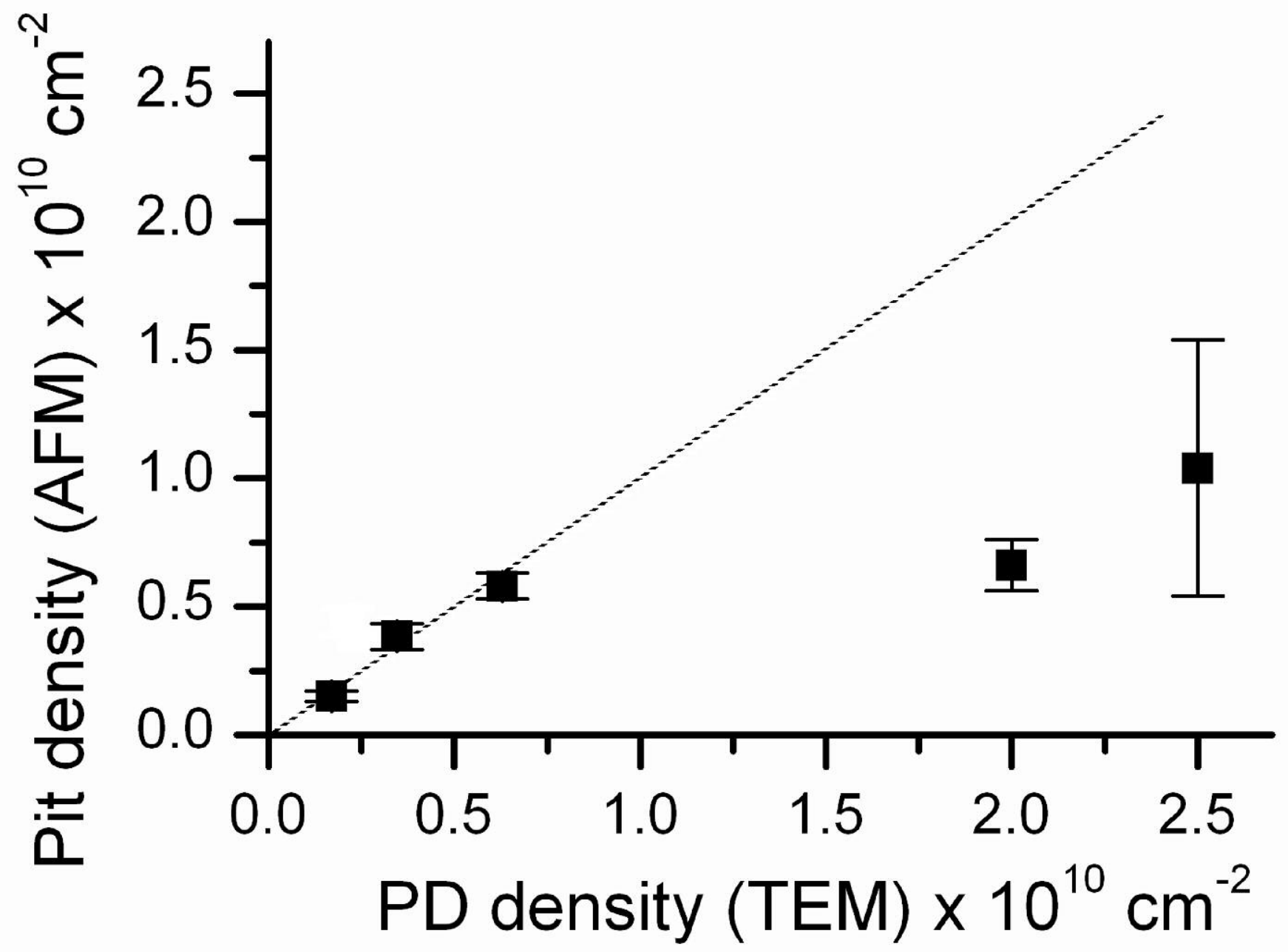

Figure 3 (FIG-3.tif) 


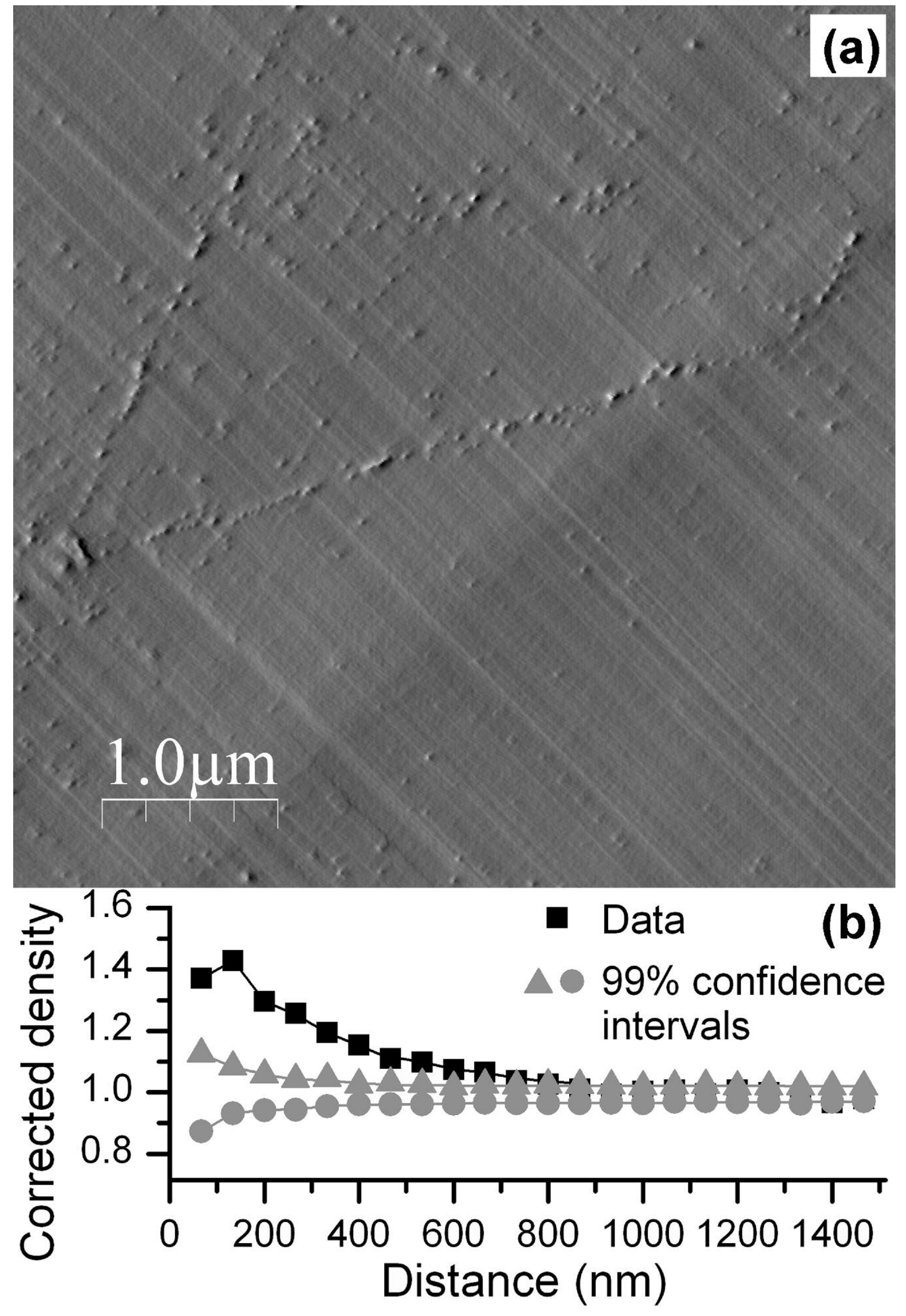

Figure 4 (FIG-4.tif) 


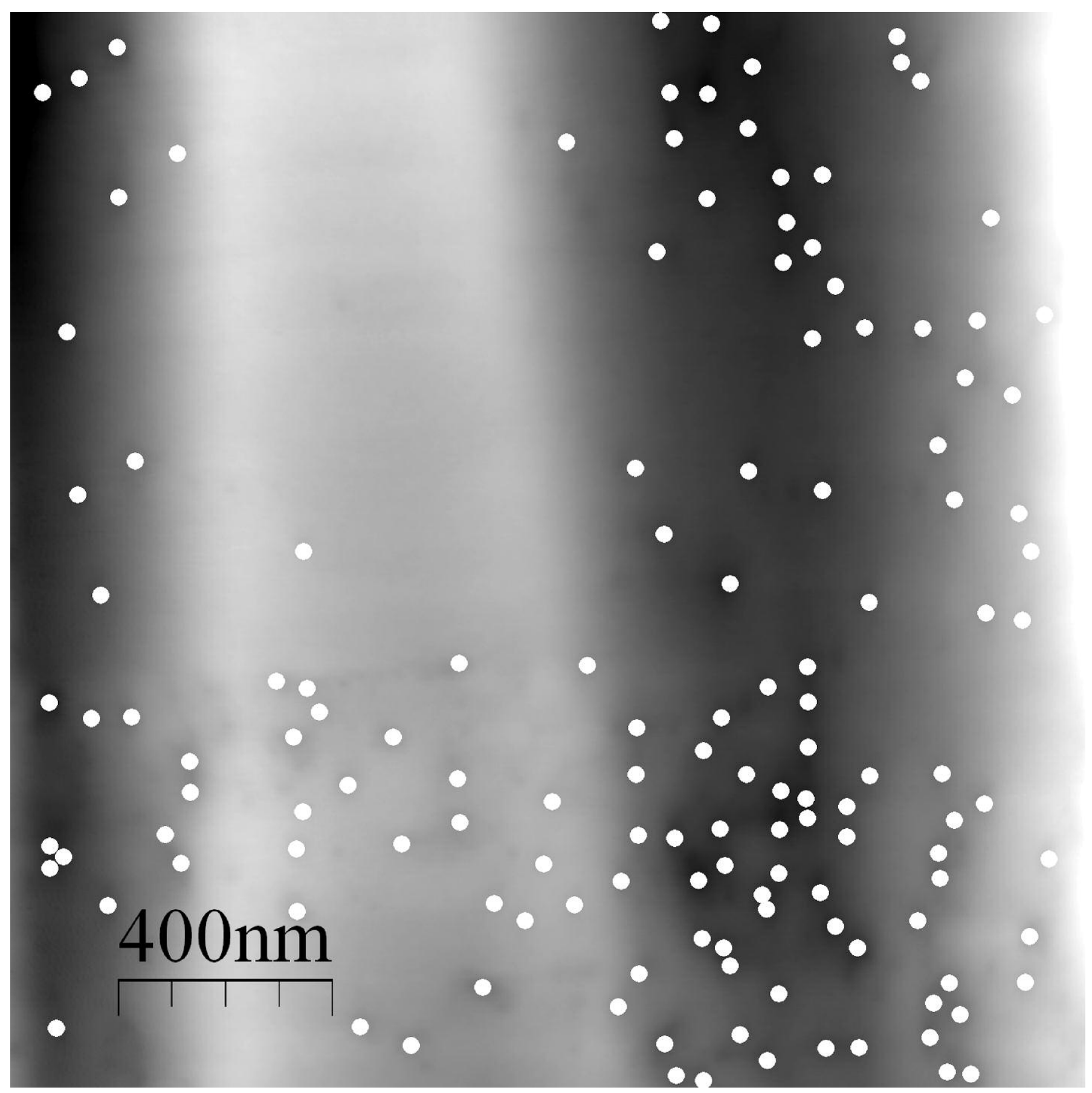

Figure 5 (FIG-5.tif) 